\title{
PARTICIPAÇÃO SOCIAL EM SANEAMENTO: VÍDEO AULAS APLICADAS A UM PROCESSO DE FORMAÇÃO
}

\section{SOCIAL PARTICIPATION IN SANITATION: VIDEO CLASSES APPLIED TO A TRAINING PROCESS}

\author{
Isabela Tsutiya Andrade \\ Engenheira Sanitarista e Ambiental \\ isa.t.andrade@gmail.com
}

Cezarina Maria Nobre Souza

Eng. Sanitarista, Dra. em Saúde Pública, Prof. Dra. do Instituto Federal do Pará

\section{Pedro Antônio Araújo da Silva}

Geógrafo e mestrando em Geografia pela Universidade Federal da Grande Dourados

\section{Luiz Roberto Santos Moraes}

Eng. Civil e Sanitarista, PhD em Saúde Ambiental

\begin{abstract}
RESUMO
Com vistas a contribuir para a superação da baixa participação social no campo do saneamento básico, como trabalho de conclusão do curso de extensão Direitos Humanos à Água e ao Saneamento (DHAS), promovido pelo Observatório Nacional dos Direitos à Água e ao Saneamento (ONDAS), foi criado o minicurso Participação Social em Saneamento. Seu objetivo foi oferecer capacitação sobre a participação social em saneamento, estando voltado para atender as necessidades/interesses de indivíduos e comunidades, associações e instituições que atuam na área. Apresenta-se a experiência de elaboração do minicurso, baseada em uma revisão da literatura, como também sua aplicação a um grupo de quatro voluntários. O minicurso contempla três subtemas (conceito de participação; formas e exemplos de organização comunitária; conselhos de saneamento), organizados em três vídeo-aulas.
\end{abstract}

Palavras-chave: Participação Social. Organização Comunitária. Conselho. Saneamento. Direitos Humanos.

\begin{abstract}
In order to contributing to overcoming the low social participation in the field of basic sanitation, as a conclusion of the extension course Human Rights to Water and Sanitation (DHAS), promoted by the National Observatory for the Rights to Water and Sanitation (ONDAS), the Social Participation in Sanitation mini-course was created. Its objective was to provide training on social participation in sanitation, focusing on meeting the needs/interests of individuals and communities, associations and institutions that work in the area. The experience of preparing the short course is presented, based on a literature review, as well as its application to a group of four volunteers. The short course includes three subthemes (concept of participation; forms and examples of community organization; sanitation councils), organized in three video classes.
\end{abstract}

Keywords: Social Participation. Community Organization. Council. Sanitation. Human Rights.

\section{INTRODUÇÃO}

De fato, a área de saneamento é historicamente marcada por significativo deficit de democracia nas políticas públicas e na gestão dos serviços. Essa característica, herdada de períodos da vida nacional caracterizados pelo autoritarismo (SOUZA, 2016), em pleno século XXI, ainda não foi superada satisfatoriamente, mesmo depois da Constituição Federal de 1988, considerada como sendo o marco central que institucionaliza a participação social no Brasil (SOUZA; HELLER, 2019). 


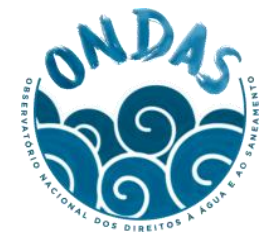

Diversos estudos (MELO, 2009; PITERMANN, 2013; MELLO; REZENDE, 2014; SOUZA, 2015; SOUZA, 2017; SOUZA; HELLER, 2019a; SOUZA; HELLER, 2019b; BRITO et al., 2020) têm demonstrado tal deficit, ainda mais aprofundado com a extinção de um conselho que atuava no campo da política de saneamento - o Conselho Nacional das Cidades (ConCidades) - pelo governo atual. Aliás, tal governo, em ampla escala e em associação a medidas de criminalização dos movimentos sociais (SENNA, 2019), vem conduzindo um processo de "desdemocratização" no país, à medida em que restringe a articulação dos setores que compõem a sociedade civil e o controle social, obstaculizando a fiscalização das ações que promove, o que configura uma ameaça à democracia (LIMA, 2020).

Com vistas a contribuir para a alteração e a superação desse quadro no campo do saneamento básico, como trabalho de conclusão do curso de extensão Direitos Humanos à Água e ao Saneamento (DHAS), promovido pelo Observatório Nacional dos Direitos à Água e ao Saneamento (ONDAS), foi criado o minicurso Participação Social em Saneamento. O minicurso busca oferecer capacitação sobre a participação social em saneamento, estando voltado para atender as necessidades/interesses de indivíduos e comunidades, associações e instituições que atuam na área.

Este texto vem apresentar a experiência de elaboração do minicurso, como também relata sua aplicação a um grupo de voluntários.

\section{METODOLOGIA}

Foi realizada revisão da literatura sobre participação social em geral e especificamente sobre a temática em questão, com base na qual foram estabelecidos os subtemas de interesse. Na sequência, partiu-se para a elaboração de slides eletrônicos e posterior montagem de vídeo aulas, utilizando-se a plataforma de design gráfico CANVA.

Foi realizada aplicação do minicurso, para fins de avaliação. Participaram dessa etapa quatro voluntários residentes no município de Salvador (BA), cujo perfil é revelado na Tabela 1. Todos e todas foram indicados por meio de pessoa que integra a rede de contatos de um dos autores, a qual também participou do minicurso.

Tabela 1 - Participantes do minicurso.

\begin{tabular}{c|c|c}
\hline Participante & Características & $\begin{array}{c}\text { Motivação para Participar } \\
\text { (ipisis litteris) }\end{array}$ \\
\hline P1 & $\begin{array}{c}\text { Mulher, 50 anos, secretária de associação comunitária, } \\
\text { secretária do instituto esporte cidadania inclusão social, } \\
\text { suplente de conselho distrital de saúde }\end{array}$ & $\begin{array}{c}\text { Aprendizado, qualificar e } \\
\text { ressaltar novos aprendizados }\end{array}$ \\
\hline P2 & $\begin{array}{c}\text { Mulher, 48 anos, assistente social, atua em organização } \\
\text { ambiental e cultural que visa à preservação e } \\
\text { conservação da fauna e da flora e a promoção da cultura }\end{array}$ & $\begin{array}{c}\text { [...] seu conteúdo faz parte das } \\
\text { atividades que realizo.[...] } \\
\text { adquirir conhecimento nessa } \\
\text { área é importante. }\end{array}$ \\
\hline P3 & $\begin{array}{c}\text { Homem, 45 anos, pedagogo, conselheiro distrital de } \\
\text { saúde; coordenador de entidade }\end{array}$ & $\begin{array}{c}\text { Qualificação para poder atuar } \\
\text { melhor }\end{array}$ \\
& $\begin{array}{c}\text { Homem, 54 anos, desenhista/artesão, conselheiro } \\
\text { comunitário, membro de organização social na } \\
\text { comunidade onde vive }\end{array}$ & $\begin{array}{c}\text { Desejo de somar, ajudar, ter } \\
\text { boa consicência perante si e a } \\
\text { sociedade, [...]. }\end{array}$
\end{tabular}

Cada participante recebeu, por e-mail, o link de acesso a um formulário com perguntas provocativas sobre os temas discutidos nas vídeo aulas. Os objetivos desta etapa foram: 1) ensejar reflexões acerca 
do tema em estudo no contexto de sua realidade local; 2) diagnosticar e registrar seu nível de conhecimento acerca da temática.

As perguntas realizadas foram: 1) Como é o saneamento no lugar onde você mora?; 2) Qual a sua relação com a água? Como é a qualidade da água que chega na sua casa?; 3) Você pensa em alguma forma de organização da comunidade para pensar o saneamento que se quer?; 4) Você já ouviu falar de Participação Social? Se sim, conte um pouco sobre a sua experiência/conhecimento; 5) Existe um Conselho de Saneamento no seu município? Você tem algum conhecimento sobre como é a atuação dos conselhos?; 6) Você tem conhecimento de Políticas Públicas em saneamento no seu município?

Na sequência, os participantes, após terem respondido ao formulário, receberam os links de acesso aos vídeos. Por fim, foram convidados a responder novamente ao questionário, em uma segunda rodada, para que se obtivesse meios de avaliar seu aprendizado, comparativamente com a primeira rodada de respostas.

\section{RESULTADOS ALCANÇADOS}

\subsection{O minicurso}

Foram selecionados três subtemas sobre os quais os vídeo aulas versaram: conceito de participação; formas e exemplos de organização comunitária; conselhos de saneamento. O endereço para o acesso ao minicurso é: https://drive.google.com/drive/folders/1b_IopJ3tzL8q3ASRjca20xdjZ2PCoYh?usp=sharing

\section{Vídeo aula 1 - O que é participação}

Por se tratar do primeiro vídeo, o primeiro tópico apresentado versou sobre o ONDAS. Em seguida, fez-se breve introdução sobre o curso. Já iniciando o curso, foram realizadas perguntas sobre as condições de água encanada e esgotamento sanitário e os direitos humanos envolvidos.

A ministrante introduz o tema central apresentando as definições e a legislação relacionada à participação e ao controle social. Quando contextualizado dentro do saneamento, o vídeo apresenta quais as funções do controle social, os aspectos básicos contemplados e as dificuldades geralmente encontradas. Por fim, é indicada alguma bibliografia correlata para um conhecimento mais aprofundado.

\section{Vídeo aula 2 - Organização comunitária}

$\mathrm{O}$ vídeo inicia com perguntas provocativas sobre o tema para inserir os participantes em uma esfera que tenha como pontos principais a comunidade, o território onde vivem, a qualidade do saneamento e as possibilidades de organização comunitária. Em seguida, aborda a definição de organização comunitária, quais os benefícios e resultados que ela alcança e a relação com os Direitos Humanos à Água e ao Esgotamento Sanitário, como no quesito de gestão participativa.

Após a contextualização sobre o que é a organização comunitária, são apresentados, de forma simplificada, os passos iniciais para mobilizar a comunidade e iniciar uma mobilização comunitária para a participação social. Por fim, o vídeo apresenta diversos formatos e exemplos de organização comunitária focadas no saneamento oriundos de diversas regiões do Brasil, bem como algumas referências.

\section{Vídeo aula 3 - Conselhos de saneamento}

O terceiro e último vídeo discute sobre as políticas públicas e os conselhos de saneamento, de forma a contemplar os assuntos abordados nos vídeos anteriores e apresentar uma forma mais concreta e existente de participação social em saneamento. $\mathrm{O}$ vídeo também apresenta a situação do acesso ao saneamento no cenário brasileiro, bem como a distribuição dos conselhos de saneamento no Brasil. 
O ministrante apresenta alguns desafios que existem para a institucionalização desses coletivos e, ao final, traz perguntas reflexivas sobre controle social, além de fazer um convite incentivando a participação democrática da população na criação, implementação e avaliação de políticas públicas.

\section{2 - Experiência de capacitação e avaliação do minicurso}

As Tabelas 2 a 5 apresentam algumas das respostas dos participantes nas duas rodadas de aplicação do formulário.

Tabela 2 - Palavras chaves dos participantes frente a pergunta: Como é o saneamento no lugar onde você mora?

\begin{tabular}{c|c}
\hline Participante & Respostas \\
\hline $\mathrm{P} 2$ & {$[. .$.$] o saneamento básico é muito precário, ainda existem bairros na periferia de Salvador$} \\
& $\begin{array}{c}\text { convivendo com esgoto à céu aberto, não tem sistema de esgoto [...] } \\
\text { P3 }\end{array}$ \\
\hline & O...]Ruas sem ligações na rede de esgoto, [...] ligações indevidas junto a rede de água pluvial. \\
\hline
\end{tabular}

Tabela 3 - Palavras chaves dos participantes frente as perguntas: Qual a sua relação com a água? Como é a qualidade da água que chega na sua casa?

\begin{tabular}{c|c}
\hline Participante & Respostas \\
\hline P1 & Relação de uso coditiano, qualidade é boa \\
\hline P2 & Minha relação com água é ótima, [...]. Aparentemente limpa, ela não apresenta sujeira visível. \\
\hline P3 & Acredito ter uma boa e responsável relação. [...] a água chega em boa qualidade. [...] \\
\hline P4 & Responsável. Percebe-se, muitas vezes, que o uso do cloro é um incômodo. \\
\hline
\end{tabular}

Tabela 4 - Palavras chaves dos participantes frente as perguntas: Você pensa em alguma forma de organização da comunidade para pensar o saneamento que se quer?

\begin{tabular}{c|c}
\hline Participante & Respostas \\
\hline $\mathrm{P} 1$ & Não. \\
\hline $\mathrm{P} 2$ & Nunca parei pra pensar nesse problema. \\
\hline $\mathrm{P} 3$ & $\begin{array}{r}\text { Sim. Recentemente a Embasa, através do setor social, fez uma proposta de acompanhamento } \\
\text { das ações para melhor entendimento. Ainda temos dificuldade, pois a maioria dos jovens não } \\
\text { se interessam ou não estamos conseguindo dialogar com eles sobre o fato. }\end{array}$ \\
\hline $\mathrm{P} 4$ & Sim. Por isso decidi/aceitei fazer parte de uma Instituição e de um Conselho Comunitário. \\
\hline
\end{tabular}

Tabela 5 - Palavras chaves dos participantes frente as perguntas: Você já ouviu falar de Participação Social? Se sim, conte um pouco sobre a sua experiência/conhecimento.

\begin{tabular}{c|c}
\hline Participante & Respostas \\
\hline P1 & Não \\
\hline
\end{tabular}




\begin{tabular}{c|c}
\hline P2 & Sim. Ajudo na distribuição de cestas básicas na minha comunidade. \\
\hline $\mathrm{P} 3$ & $\begin{array}{c}\text { Sim, muito. A minha experiência é conflituosa, pois geralmente a gestão governamental não } \\
\text { valoriza a vivência e experiência comunitária. Por outro lado, os moradores tendem a aceitar } \\
\text { o que é ofertado com medo de "perder" o que têm devido a falta de acesso as informações } \\
\text { necessárias. Participar é atuar de forma cidadã. Exigir que o direito à Cidadania seja } \\
\\
\text { cumprido. Acompanhar as discussões dos Conselhos de direitos, LOAS, LDO, PPA ajudam a } \\
\text { troca de conhecimentos e experiências, facilitando o exercício do controle social. }\end{array}$ \\
& $\begin{array}{c}\text { Sim. Como percebi as muitas necessidades de amparo e esclarecimento para uma população } \\
\text { leiga e desinformada e tendo um irmão ativo na vida social da comunidade, percebi que eu } \\
\text { também tinha que estar alerta e participativo; uma questão de empatia, primeiramente. }\end{array}$
\end{tabular}

Analisando os resultados, observa-se que $100 \%$ dos participantes do minicurso se consideram usuários responsáveis de água, apresentando uma relação respeitosa e consciente com ela. Além disso, as condições de saneamento para todos os participantes não passa de regular, observando-se, portanto, um deficit na prestação dos serviços na cidade de Salvador e, consequentemente, uma carência na atuação ativa da comunidade exigindo melhores condições de saneamento.

Dentre os participantes, $75 \%$ já teve algum contato com o termo participação social e têm algum tipo de atuação na comunidade. Portanto, já existe um saber sobre a importância da articulação comunitária em prol de melhorias comuns, mas o âmbito em questão ainda não é tido como prioridade.

O minicurso instigou o interesse dos participantes em saber como se organizar de forma comunitária para pensar o saneamento na comunidade, como pode ser visto na fala do participante 3 , ao dizer "...com o aprendizado do curso teremos um melhor direcionamento" para pensar quais as melhores condições de saneamento que a comunidade deseja.

Os participantes também não tinham conhecimento sobre a existência de conselho de saneamento no município, mas, a partir do conteúdo apresentado no minicurso, as respostas foram mais acertivas em relação ao tema. Pode-se dizer que o conteúdo do terceiro vídeo foi eficiente na explicação e contextualiazção das atribuições de um conselho, facilitando, portanto, o entendimento e as respostas dos participantes.

O mesmo pode-se dizer para a pergunta referente às Políticas Públicas. As respostas, após a interação com os vídeos, foram mais acertivas e contextualizadas.

\section{CONCLUSÃO}

A aplicação do curso com o pequeno grupo de voluntários rendeu frutos positivos, visto que houve um aumento no interesse acerca do tema, bem como serviu de apredizado sobre o saneamento. Fica claro que o curso não visa à mobilização social, mas, sim, constitui uma forma de incentivar pessoas chaves e centrais em comunidades a iniciarem essa mobilização no território de atuação, com os devidos instrumentos e ferramentas necessários.

É de grande interesse que o minicurso seja difundido, aplicado e reaplicado em diferentes comunidades e realidades para que, de fato, a questão dos direitos humanos à agua e ao saneamento e a existencia do controle social se tornem conhecidos no cenário nacional.

Vale ressaltar que o minicurso pode ser utilizado como ferramenta para uma mobilização social ainda maior, com mais vivências, acompanhamento e trocas presenciais dentro da comunidade. 


\section{AGRADECIMENTOS}

Gostaríamos de agradecer, em especial, aos participantes do minicurso que, de forma voluntária, estiveram interessados no tema e dispostos a assistir aos vídeos e responder os formulários. De fato, o minicurso só tem qualquer valor quando aplicado em uma comunidade. Agradecemos também a toda equipe do Observatório Nacional de Direitos Humanos à Água e ao Saneamento (ONDAS) pela facilitação do curso e incentivo na luta em prol da universalização do saneamento, dos direitos humanos e da participação comunitária.

\section{REFERÊNCIAS}

BRITO, D.A.C; SEABRA, L.C; LIMA, P.M; SOUZA, C.M.N. Manejo de resíduos sólidos e de águas pluviais: o (des)controle social em belém, pará Gesta, v. 8, n. 2, p. 103 - 118, 2020.

LIMA, I.C. Do Processo de Desdemocratização: uma análise da redução da participação social no brasil no governo Bolsonaro. SIMPÓSIO INTERNACIONAL ESTADO, SOCIEDADE E POLÍTICAS PÚBLICAS, III., 2020, Teresina. Anais... Teresina: | Programa de Pós-graduação em Políticas Públicas/Universidade Federal do Piauí, 2020. Disponível em: https://sinespp.ufpi.br/upload/anais/NTc5.pdf?113936. Acesso em: 10 out. 2021.

MELLO, M.C.C.; REZENDE, S. O Conselho Municipal de Saneamento de Belo Horizonte: desafios e possibilidades. Engenharia Sanitária e Ambiental, vol. 19, n. 4, p. 479-488, 2014.

MELO, G.B. Avaliação da Política Municipal de Saneamento Ambiental de Alagoinhas (BA): Contornos da participação e do controle social. Dissertação de mestrado. Brasília: Universidade de Brasília, 2009.

PITERMAN, A. (A falta de) Controle social das políticas municipais de saneamento: um estudo em quatro municípios de Minas Gerais. Saúde e Sociedade, vol. 22, n. 4, p. 1.180-1.192, 2013.

SENNA, M.C.M Que vozes querem calar? Ameaças às instituições participativas no início do governo Bolsonaro. Análise de Conjuntura. Centro de Estudos Estratégicos da FIOCRUZ. 2019. Disponível em: https://cee.fiocruz.br/?q=ANALISE-DE-CONJUNTURA. Acesso em: 10 Out. 2021.

SOUZA. C.M.N. Participação dos cidadãos na gestão do saneamento básico no Pará. Novos Cadernos NAEA, v. 18 n. 2, p. 261-274, 2015.

SOUZA, C.M.N. Participação dos cidadãos e saneamento básico: panorama da legislação nacional. Revista do Instituto de Estudos Brasileiros, n. 63, 2016.

SOUZA. C.M.N. Gestão da água e saneamento básico: reflexões sobre a participação sociaL. Saúde Soc. São Paulo, v.26, n.4, p.1058-1070, 2017.

SOUZA. C.M.N; HELLER, L. O controle social em saneamento e em saúde: análise comparativa com base nos marcos legais federais brasileiros. Ciência \& Saúde Coletiva, v. 24, n.1, 2019a.

SOUZA. C.M.N; HELLER, L. Efetividade deliberativa em conselhos municipais de saneamento e de saúde: um estudo em Belo Horizonte-MG e em Belém-PA Ciência \& Saúde Coletiva, v. 24, n. 11, 2019b. 